\title{
Comparison of cognitive performance and aspects of the care context in elderly caregivers in Brazil
}

\author{
A follow-up study
}

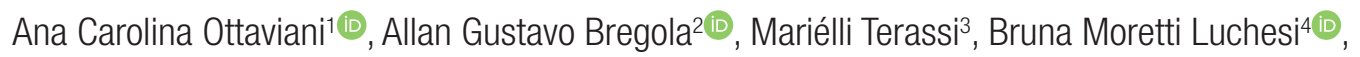 \\ Érica Nestor Souza ${ }^{1}$, Nathalia Alves de Oliveira ${ }^{1}$, Francisco José Fraga ${ }^{5}$, Sofia Cristina lost Pavarini ${ }^{1}$
}

ABSTRACT. Cognitive health is important for the quality of life and well-being of elderly caregivers. Cognitive impairments can negatively affect the ability to care for oneself and others. Objective: To compare cognitive performance and aspects of the care context in elderly caregivers of older adults in a three-year follow-up investigation Methods: A longitudinal study was conducted of 61 elderly caregivers treated in primary care in a city in the interior of the state of São Paulo with data collected in 2014 and 2017. Sociodemographic characteristics, the care context, cognition, performance for activities of daily living, burden and depressive symptoms were collected in individual interviews. Data analysis was performed to compare categorical and continuous variables. Results: Significant increases were found between baseline and follow-up for the language domain score of the cognitive evaluation $(p=0.024)$, receipt of material support $(p=0.020)$, time providing care $(p=0.045)$ and dependence of elderly care recipient for basic activities of daily living ( $p=0.042)$. Conclusion: Elderly caregivers performed better on the domain of language, received more material/financial support, spent more time on care and reported greater dependence of the elderly care recipient. Key words: aged, caregivers, cognition, mental health, primary health care.

\section{COMPARAÇÃO DO DESEMPENHO COGNITIVO E ASPECTOS DO CONTEXTO DO CUIDADO EM IDOSOS CUIDADORES IDOSOS NO BRASIL: UM ESTUDO DE ACOMPANHAMENTO}

RESUMO. A saúde cognitiva é importante para a qualidade de vida e bem-estar dos cuidadores idosos. 0 comprometimento cognitivo pode afetar negativamente a capacidade de cuidar de si e dos outros. Objetivo: Comparar o desempenho cognitivo e os aspectos do contexto do cuidado em idosos cuidadores de idosos em uma de acompanhamento de três anos. Métodos: Trata-se de um estudo longitudinal com medidas em 2014 e 2017, realizado com 61 cuidadores idosos cadastrados na atenção primária de um município do interior do Estado de São Paulo. Características sociodemográficas, contexto do cuidado, cognição, desempenho nas atividades da vida diária, sobrecarga e sintomas depressivos foram coletados em entrevistas individuais. A análise dos dados foi realizada para comparar variáveis categóricas e contínuas. Resultados: Foram encontrados aumentos significativos entre a linha de base e o acompanhamento do escore no domínio da linguagem da avaliação cognitiva $(p=0,024)$, receber ajuda material $(p=0,020)$, tempo de cuidado $(p=0,045)$ e dependência do idoso em relação às atividades básicas da vida diária $(p=0,042)$. Conclusão: Os cuidadores de idosos tiveram melhor desempenho no campo da linguagem, passaram a receber mais apoio material / financeiro, experimentaram aumentos no tempo gasto no cuidado e na dependência do idoso. Palavras-chave: idosos, cuidadores, cognição, saúde mental, atenção primária à saúde.

This study was conducted at the Federal University of São Carlos, Graduate Program in Nursing, São Carlos, SP, Brazil.

${ }^{1}$ Federal University of São Carlos, Graduate Program in Nursing, São Carlos, SP, Brazil. ${ }^{2}$ School of Health Sciences, University of East Anglia, Norwich, United Kingdom. ${ }^{3}$ Central Paulista University Center, São Carlos, SP, Brazil. ${ }^{4}$ Federal University of Mato Grosso do Sul, Três Lagoas Campus, Graduate Program in Nursing, Três Lagoas, MS, Brazil. ${ }^{5}$ Federal University of ABC (UFABC), Engineering, Modeling and Applied Social Sciences Center (CECS), Santo André, SP, Brazil.

Ana Carolina Ottaviani. Graduate Program in Nursing, Federal University of São Carlos (UFSCar) - Rodovia Washington Luís Km 235 - $13565-905$ São Carlos SP - Brazil. E-mail: carol.ottaviani@gmail.com

Disclosure: The authors report no conflicts of interest.

Received November 12, 2019. Accepted in final form February 21, 2020.

(c) BY 
$C^{\mathrm{h}}$ hanges in the demographic and epidemiological profile of the population have resulted in a higher frequency of chronic conditions, which can compromise the functional capacity of elderly individuals, leading to the need for daily care. ${ }^{1}$ Culturally, care in Brazil occurs in the family environment. Brazilian caregivers are mostly women (wife or daughter of the care recipient), in a stable relationship (married or with a long-term partner), middle-aged (45 to 50 years), have a low level of education and provide care for more than ten hours a day ${ }^{2-4}$ Moreover, some studies show there is a growing number of people over 60 who play the role of informal caregiver of another more dependent elder. ${ }^{5-7}$

While the task of providing care can offer benefits and positive results, there is a high rate of excessive burden resulting from emotional stress, physical exhaustion and health problems, as well as limitations in terms of social and leisure activities. ${ }^{8-10}$ Providing care is a complex, challenging task that can exert an impact on the mental and physical health of the caregiver. ${ }^{11}$ As cognitive performance is important to the quality of life and wellbeing of elderly caregivers, cognitive decline can negatively affect their ability to provide care and even perform self-care. ${ }^{12}$ Studies have shown that elderly caregivers have poorer performance on tasks of cognitive processing, executive functions, attention and memory. ${ }^{13-15}$

Another issue that requires further evidence in studies on cognitive health, particularly among caregivers, relates to emotional health. High levels of stress resulting from the burden of providing daily care can jeopardize the cognitive health of caregivers ${ }^{5,15,16}$ A systematic review reported high levels of stress in family caregivers of elderly individuals with dementia, resulting in poorer performances with regard to attention and executive functions; however, interventions with the aim of reducing stress are reported to improve cognition. ${ }^{17}$ A study involving 252 elderly caregivers of older adults with dementia compared to demographically matched noncaregiver controls found that cognitive performance was similar in both groups, but the caregivers had higher levels of stress and depressive symptoms. ${ }^{18}$

The literature shows the importance of preserving cognitive domains for the planning and execution of care tasks. Given the characteristics of elderly caregivers, the cognitive health of this population has become an emerging research topic, as well as a public health problem, since a decline in this aspect jeopardizes the caregiver's ability to provide care for a loved one and perform self-care. ${ }^{12}$

Investigations of the impact of caring on the cog- nitive performance of caregivers remain controversial and few studies assess elderly caregivers of older adults. Thus, the aim of the present study was to compare cognitive performance and aspects of the care context in elderly caregivers of older adults in a three-year followup investigation.

\section{METHODS}

\section{Participants}

A longitudinal study with a three-year follow-up was conducted using data from a survey entitled "Follow-up of elderly caregivers in primary care", involving elderly caregivers of older adults from a city in the state of São Paulo, Brazil.

The baseline study was conducted from April to November 2014, involving a convenience sample selected from households listed by the 15 Family Health Units, in which two or more older adults resided. The sample consisted of 142 elderly caregivers who met the following inclusion criteria: 60 years of age or older, registered with one of the 15 Family Health Units in the city and being the primary caregiver of a dependent elderly individual living in the same household. Dependence on the part of the elderly care recipient was defined as requiring assistance for at least one activity of daily living (ADL) and/or instrumental activity of daily living (IADL) according to the Katz Index ${ }^{19}$ and the Lawton and Brody Scale. ${ }^{20}$ In this study, a low cognitive test score was not considered an exclusion criterion, but candidates with communication difficulties preventing their understanding of the questions were excluded.

Follow-up data collection was conducted from January to July 2017 and all households were revisited. Twenty-six participants were excluded due to the death of the caregiver, 21 were excluded because the participants had either moved from the city or were not located at their homes after three attempts, 18 were no longer caregivers because the dependent elderly individual had either died or required professional care and 16 refused to participate. Thus, 61 elderly caregivers were submitted to a second evaluation.

\section{Measures}

Data were collected through previously scheduled at-home interviews conducted by trained researchers. The interviews took place in a single session, lasting approximately one hour and thirty minutes.

Caregivers were asked to provide information on sociodemographic characteristics, collected using a 
questionnaire devised by the researchers, addressing sex (female or male), age (years), education (years), marital status (married, single, divorced or widowed) and ethnicity (white, brown/mulatto or black). Care characteristics were evaluated using a questionnaire inquiring about the relationship between caregiver and care recipient (spouse, father/mother, father-in-law/motherin-law or brother/sister), time (months) the participant has been providing care, the number of hours/day spent on providing care, whether the participant had received material and/or emotional support (yes/no) and whether the participant had received support from religious groups with regard to providing care (yes/no).

Cognition was assessed using Addenbrooke's Cognitive Examination-Revised (ACE-R), which is composed of five domains: orientation/attention (18 points), memory (26 points), verbal fluency (14 points), language (26 points) and visuospatial skills (16 points). The total ACE-R score ranges from 0 to 100 points. ${ }^{21}$ In the present study, the ACE-R score was treated as a continuous variable.

Depressive symptoms were assessed using the Geriatric Depression Scale (15-item version), whose final score is determined by summing the item scores. ${ }^{22}$ For this study, a total score $\leq 5$ points was considered indicative of the absence of depressive symptoms, whereas $\geq 6$ points was considered indicative of the presence of depressive symptoms.

Perceived burden was identified using the Brief version of the Zarit Burden Interview (ZBI), composed of 12 items scored on a five-point scale: 0 (not at all) to 4 (always). Total score ranges from 0 to 48 points, with higher scores denoting greater perceived burden ${ }^{23,24}$ For the analysis, the median of the total score was considered (caregivers with scores above and below the median were considered as having high and low burden, respectively).

\section{Ethics}

This study received approval from the Human Research Ethics Committee of the Federal University of São Carlos (certificate number: 80458017.7.0000.5504). Participation was voluntary and all participants signed a statement of informed consent.

\section{Statistical analysis}

The data were analyzed with the aid of the Statistical Analysis System (SAS) for Windows, version 9.2. Descriptive statistics were performed. Categorical variables were expressed as absolute and percentage frequencies, while continuous variables were expressed as mean and standard deviation values. Pearson's Chisquare test was used to compare the categorical variables. Due to the non-normal distribution between the two measurements, the Mann-Whitney test was used for the continuous variables. McNemar's test was used to compare the numerical variables between measurements. The Wilcoxon test for related samples was used due to the absence of a normal distribution. A $5 \%$ significance level was adopted for the statistical tests $(\mathrm{p} \leq 0.05)$.

\section{RESULTS}

At the 2014 evaluation, most elderly caregivers were female ( $\mathrm{n}=52 ; 85.2 \%)$, with a mean age of 67.85 years $( \pm 5.41)$, married $(n=52 ; 85.2 \%)$ and retirees $(n=39$; $63.9 \%)$. Mean educational level was 3.72 years $( \pm 3.4)$, with a predominance of elementary school education $(\mathrm{n}=48 ; 78.7 \%)$. The majority of caregivers provided care to a spouse ( $\mathrm{n}=52 ; 85.2 \%)$. Table 1 displays the data on cognitive performance and care variables at the first and second evaluations.

On the cognitive test, a significant increase in the language domain was found at the follow-up evaluation compared to baseline $(\mathrm{p}=0.024)$. Regarding the care variables, significant increases between the first and second evaluations were found for receiving material/financial support $(\mathrm{p}=0.020)$, time providing care $(\mathrm{p}=0.045)$ and the dependence of the elderly care recipient for activities of daily living ( $\mathrm{p}=0.042)$ (Table 1 ).

\section{DISCUSSION}

The socio-demographic characteristics of the elderly caregivers in the present investigation are similar to those described in national and international studies, with a predominance of married, retired women with low educational level who provide care for a spouse. . $^{4,5,25}$

Regarding cognitive performance, the elderly caregivers showed an increase between baseline and final evaluations in scores on the ACE-R domains, although the only significant increase was in the language domain. These findings differ from data described in previous studies, which report that caregivers, especially caregivers of an individual with dementia, experience a decline in cognitive performance. ${ }^{15,18}$

However, tasks linked to caring can be cognitively complex, requiring attention, judgment and problemsolving skills, ${ }^{11}$ which may exert a positive influence on the cognitive functioning of informal caregivers. Indeed, a population-based study involving elderly caregivers found that informal care may be beneficial to cogni- 
Table 1. Cognitive performance and variables of care context among elderly caregivers at both evaluations $(n=61)$, São Carlos-SP, Brazil, 2014-2017.

\begin{tabular}{|c|c|c|c|}
\hline Variable & Baseline & Follow-up & p-value* \\
\hline \multicolumn{4}{|c|}{ Cognitive performance } \\
\hline MMSE & $22.61( \pm 4.13)$ & $23.03( \pm 3.61)$ & $0.257^{\star}$ \\
\hline ACE-R & $63.05( \pm 17.93)$ & $62.30( \pm 16.16)$ & $0.585^{\star}$ \\
\hline Orientation/attention & $13.31( \pm 2.66)$ & $13.49( \pm 2.35)$ & $0.348^{*}$ \\
\hline Memory & $14.93( \pm 5.97)$ & $14.33( \pm 5.46)$ & $0.427^{\star}$ \\
\hline Verbal fluency & $5.66( \pm 2.89)$ & $5.97( \pm 2.88)$ & $0.111^{*}$ \\
\hline Language & $17.84( \pm 5.22)$ & $18.57( \pm 4.75)$ & $0.024^{\star}$ \\
\hline Visuo-spatial & $22.61( \pm 4.13)$ & $23.03( \pm 3.61)$ & $0.257^{*}$ \\
\hline \multicolumn{4}{|c|}{ Care context } \\
\hline Time providing care (months). Mean (SD) & $11.69( \pm 13.17)$ & $14.79( \pm 16.69)$ & $0.045^{\star \star}$ \\
\hline Time spent on care (hours/day). Mean (SD) & $5.10( \pm 4.34)$ & $6.12( \pm 5.18)$ & $0.258^{\star \star}$ \\
\hline \multicolumn{4}{|l|}{ Dependence of care recipient (Katz) } \\
\hline - Independent n (\%) & $47(77.0 \%)$ & $40(65.6 \%)$ & $0.042^{\star \star \star}$ \\
\hline • Dependent n (\%) & $14(23.0 \%)$ & $21(34.4 \%)$ & \\
\hline \multicolumn{4}{|l|}{ Dependence of recipient (Lawton) } \\
\hline - Partial dependency. n (\%) & $55(90.1 \%)$ & $57(93.4 \%)$ & $0.157^{\star \star \star}$ \\
\hline - Total dependency. n (\%) & $6(9.9 \%)$ & $4(6.6 \%)$ & \\
\hline \multicolumn{4}{|l|}{ Receives material support } \\
\hline - No. n (\%) & $55(90.1 \%)$ & 48 (78.7\%) & $0.020^{\star \star \star \star}$ \\
\hline - Yes. n (\%) & $6(9.9 \%)$ & $13(21.3 \%)$ & \\
\hline \multicolumn{4}{|l|}{ Receives emotional support } \\
\hline - No. n (\%) & $31(50.8 \%)$ & $32(52.5 \%)$ & $0.853^{\star \star \star *}$ \\
\hline - Yes. n (\%) & $30(49.2 \%)$ & $29(47.5 \%)$ & \\
\hline - ZBI. Mean(SD) & $7.18( \pm 8.01)$ & $8.46( \pm 8.80)$ & $0.193^{*}$ \\
\hline - ZBI >median. $n(\%)$ & $34(55.7 \%)$ & $32(52.5 \%)$ & $0.670^{\star \star \star}$ \\
\hline - ZBI <median. $\mathrm{n}(\%)$ & $27(44.3 \%)$ & $29(47.5 \%)$ & \\
\hline - GDS total. Mean (SD) & $4.08( \pm 2.70)$ & $3.68( \pm 2.68)$ & $0.250^{*}$ \\
\hline - No symptoms. n (\%) & $45(75.0 \%)$ & $47(78.3 \%)$ & $0.617^{\star \star \star}$ \\
\hline • With symptoms. n (\%) & $15(25.0 \%)$ & $13(21.7 \%)$ & \\
\hline
\end{tabular}

*Wilcoxon test; **Mann-Whitney test; ${ }^{\star \star \star}$ MCNemar's test; ${ }^{\star \star \star \star P e a r s o n ' s ~ C h i-s q u a r e ~ t e s t ; ~ M M S E: ~ M i n i-M e n t a l ~ S t a t e ~ E x a m i n a t i o n ; ~ A C E-R: ~ A d d e n b r o o k e ' s ~ C o g n i t i v e ~ E x a m i-~}$ nation-Revised; ZBI: Zarit Burden Interview; GDS: Geriatric Depression Scale; SD: standard deviation. 
tive function, especially for female caregivers. ${ }^{12}$ Providing care is an activity that requires adequate cognitive processing and strong performance regarding cognitive skills, such as attention, memory, planning, and logical reasoning. ${ }^{13}$

Informal care can involve everything from physical tasks to psychological activities, which differ in terms of cognitive involvement and intensity. Therefore, the effects on cognition may vary according to the type of care provided. ${ }^{12}$ Psychological well-being is a central factor in cognitive performance, where caregivers can present with a cognitive deficit in specific functions, sometimes associated with burden, stress or depressive symptoms. ${ }^{6,13,26,27}$ In the present study, the elderly caregivers exhibited low levels of care-related burden and depressive symptoms. A review of population-based studies involving informal caregivers found that low levels of carerelated stress are associated with the benefits of caring. ${ }^{28}$

Over the years, the age of older care recipients has increased and probably need more care, increasing the time spent on activities of daily living. The intensity of care can be a source of health effects of care. Studies have compared medium or moderate caregivers with intensive caregivers based on care hours and found greater health effects when more intensive care is provided..$^{29,30}$

A higher level of dependence of the elderly care recipient results in more time spent on care by the caregiver, reducing the time available for their other activities. The reorganization of time use by family caregivers and the provision of formal support can reduce the burden of caring and benefit the well-being of caregivers. ${ }^{31}$

In the present study, elderly caregivers reported receiving more material/financial support at follow-up compared to baseline. This finding may be related to the increasing age of older care recipients, which may increase dependence on self-care or financially. Receiving support can provide a positive view of life and stressful situations, thereby ensuring the ability to cope with adversity. ${ }^{32,33}$ Even extreme situations, such as an excessive care burden, can be minimized by social support and coping mechanisms. . $^{33,34}$

Support networks, material/emotional support and social activities are associated with better cognitive function and a lower risk of cognitive decline. ${ }^{35}$ Some studies have demonstrated the positive effects of support on psychological and physical wellbeing in caregivers. ${ }^{36,37}$

The present investigation has limitations that should be taken into account. The elderly caregivers were evaluated at two discrete timepoints, with no monitoring of the cognitive, psychological and health changes that may have occurred during the time interval between the two evaluations. We therefore suggest that future studies monitor these aspects more regularly. Another limitation involves the loss of individuals between evaluations, making it impossible to determine whether the elderly caregivers who were not reassessed improved or worsened for the aspects evaluated.

The present findings have clinical implications for care provision by older adults to other older adults. Caregivers may be somewhat younger and have greater functional capacity compared to care recipients, but special attention should be given to those who feel burdened by the care. This situation can compromise wellbeing of the caregiver, as well as the quality of the care offered.

In conclusion, the present study, at the follow-up evaluation the elderly caregivers had better performance on the language domain of cognition, spent more time on providing care, elderly care recipients were more dependent for basic activities of daily living, and caregivers received more material/financial support.

The present findings can contribute to the planning and implementation of interventions for elderly caregivers. The role of primary care services is to promote health and prevent disease. Thus, interventions aimed at stimulating physical and psychological health can improve the quality of life of older caregivers and the quality of care provided to older people.

Acknowledgments. We extend our thanks to the Coordenação de Aperfeiçoamento Pessoal de Nível Superior (Grant number 001), Conselho Nacional de Desenvolvimento Científico e Tecnológic (Grant number 304068/2015-6) and Fundação de Amparo à Pesquisa do Estado de São Paulo (Grant number 2017/04129-9) for funding the Project. The funders had no role in the study design, data collection and analysis, decision to publish, or preparation of the manuscript.

Author contributions. Ana Carolina Ottaviani: conception, planning, data collection, analysis, data interpretation and redaction. Allan Gustavo Brigola: data collection, analysis, interpretation and writing-review. Mariélli Terassi: conception, planning, data collection and writing-review. Bruna Moretti Luchesi: conception, planning, data collection and writing-review. Érica Nestor Souza: conception, planning, data collection and writing-review. Nathalia Alves de Oliveira: data collection and redaction writing-review. Francisco José Fraga: planning, analysis, data interpretation and redaction. Sofia Cristina Iost Pavarini: conception, planning, data interpretation and redaction. 


\section{REFERENCES}

1. Miranda D, Morais G, Mendes G, Cruz A, Silva A, Lucia A. Population aging in Brazil: current and future social challenges and consequences. Rev Bras Geriatr e Gerontol. 2016;19(3):507-19.

2. Melo BR de S, Diniz MAA, Casemiro FG, et al. Cognitive and functional assessment about elderly people users of health public service. Esc Anna Nery. 2017;21(4).

3. Almeida KM V, Toye C, Silveira LVA, Slatyer S, Hill K, Jacinto AF. Assessment of functional health literacy in Brazilian carers of older people. Dement Neuropsychol. 2019;13(2):180-6.

4. Anjos KF, Boery RNSO, Pereira R, et al. Association between socia support and quality of life of relative caregivers of elderly dependents. Cien Saude Colet. 2015;20(5):1321-30.

5. Luchesi BM, Alexandre TS, Oliveira NA, et al. Factors associated with attitudes toward the elderly in a sample of elderly caregivers. Int Psychogeriatrics. 2016;28(12):2079-89.

6. Brigola AG, Luchesi BM, Rossetti ES, et al. Health profile of family caregivers of the elderly and its association with variables of care: a rura study. Rev Bras Geriatr Gerontol. 2017;20(3):409-20.

7. Pavarini SCI, Neri AL, Brigola AG, et al. Elderly caregivers living in urban, rural and high social vulnerability contexts. Rev da Esc Enferm. 2017; 51(0):e03254.

8. Del-Pino-Casado R, Palomino-Moral PA, Frías-Osuna A. The Association of Satisfaction and Perceived Burden With Anxiety and Depression in Primary Caregivers of Dependent Elderly Relatives. Res Nurs Health. 2015;38(5):384-91.

9. Lino VTS, Rodrigues NCP, Camacho LAB, et al. Prevalence of overburden in caregivers of dependent elderly and associated factors in a poor area of Rio de Janeiro, Brazil. Cad Saude Publica. 2016;32(6): e00060115.

10. Vaingankar JA, Chong SA, Abdin E, et al. Psychiatric morbidity and its correlates among informal caregivers of older adults. Compr Psychiatry. 2016;68:178-85

11. Aggarwal NT, Wilson RS, Beck TL, et al. Perceived stress and change in cognitive function among adults 65 years and older. Psychosom Med. 2014;76(1):80-5.

12. Zwar L, König HH, Hajek $A$. The impact of different types of informal caregiving on cognitive functioning of older caregivers: Evidence from a longitudinal, population-based study in Germany. Soc Sci Med. 2018;214:12-9.

13. Pavarini $\mathrm{SCl}$, Brigola AG, Ottaviani AC, et al. Factors associated with cognitive performance in elderly caregivers. Arq Neuropsiquiatr. 2018; 76(10):685-91.

14. Pertl MM, Hannigan C, Brennan S, Robertson $\Vdash H$, Lawlor BA. Cognitive reserve and self-efficacy as moderators of the relationship between stress exposure and executive functioning among spousal dementia caregivers. Int Psychogeriatrics. 2017;29(4):615-25.

15. Dassel KB, Carr DC, Vitaliano P, Pruchno R. Does caring for a spouse with dementia accelerate cognitive decline? findings from the health and retirement study. Gerontologist. 2017;57(2):319-28.

16. Stewart NJ, Morgan DG, Karunanayake CP, et al. Rural Caregivers for a Family Member with Dementia: Models of Burden and Distress Differ for Women and Men. J Appl Gerontol. 2016;35(2):150-78.

17. Allen AP, Curran EA, Duggan Á, et al. A systematic review of the psychobiological burden of informal caregiving for patients with dementia: Focus on cognitive and biological markers of chronic stress. Neurosci Biobehav Rev. 2016;73:123-64.

18. O'Sullivan M, Brennan S, Lawlor BA, Hannigan C, Robertson $\mathbb{H}$, Pert MM. Cognitive functioning among cognitively intact dementia caregivers compared to matched self-selected and population controls. Aging and Mental Health. 2018:1-8

19. Katz S, Ford AB, Moskowitz RW, Jackson BA, Jaffe MW. Studies of illness in the aged. The index of adl: a standardized measure of biological and psychosocial function. JAMA. 1963;185

20. Lawton MP, Brody EM. Assessment of older people: Self-maintaining and instrumental activities of daily living. Gerontologist. 1969;9(3):179-86.

21. Mioshi E, Dawson K, Mitchell J, Arnold R, Hodges JR. The Addenbrooke's Cognitive Examination Revised (ACE-R): a brief cognitive test battery for dementia screening. Int J Geriatr Psychiatry. 2006;21(11): 1078-85.

22. Yesavage JA, Sheikh JI. Geriatric Depression Scale (GDS): Recent evidence and development of a shorter version. Clin Gerontol. 1986;5(12): 165-73.

23. Gratão ACM, Brigola AG, Ottaviani AC, et al. Brief version of Zarit Burden Interview (ZBI) for burden assessment in older caregivers. Dement Neuropsychol. 2019;13(1):122-9.

24. Bédard M, Molloy DW, Squire L, Dubois S, Lever JA, O'donnell M. The Zarit Burden Interview: A new short version and screening version. Gerontologist. 2001;41(5):652-7.

25. Pinquart M, Sörensen S. Spouses, adult children, and children-in-law as caregivers of older adults: A meta-analytic comparison. Psychol Aging. 2011;26(1):1-14

26. Balardin JB, Palma KAXA, Garcia Junior ME, Bromberg E. Déficits cognitivos em cuidadores de pacientes com demência. Rev Bras Ciências do Envelhec Hum. 2007;4(2):55-64.

27. Yu H, Wang X, He R, Liang R, Zhou L. Measuring the caregiver burden of caring for community-residing people with Alzheimer's disease. PLoS One. 2015;10(7):e0132168.

28. Roth DL, Fredman L, Haley WE. Informal caregiving and its impact on health: A reappraisal from population-based studies. Gerontologist. 2015;55(2):309-19.

29. Bom J, Bakx P, Schut F, Van Doorslaer E. The Impact of Informal Caregiving for Older Adults on the Health of Various Types of Caregivers: A Systematic Review. Gerontologist 2019;59(5):e629-e642.

30. Wolff JL, Spillman BC, Freedman VA, Kasper JD. A National Profile of Family and Unpaid Caregivers Who Assist Older Adults With Health Care Activities HHS Public Access. JAMA Intern Med. 2016;176(3):372-9.

31. Carvalho EB, Neri AL. Patterns of use of time by family caregivers of elderly persons with dementia. Rev Bras Geriatr Gerontol. 2019;22(1): 180143.

32. Manzini CSS, Vale FAC. Resilience of family caregivers of elderly with Alzheimer. Rev Eletrônica Enferm. 2016;18:e1190.

33. Serra L, Contador I, Fernández-Calvo B, et al. Resilience and social support as protective factors against abuse of patients with dementia: A study on family caregivers. Int J Geriatr Psychiatry. 2018;33(8):1132-8.

34. Gozzoli C, Giorgi A, D’Angelo C. Protective Factors for the Well-Being in Caregivers of Patients with Alzheimer's: The Role of Relational Quality. Psychology. 2013;04(06):57-66.

35. Dam AEH, Vugt ME, Klinkenberg IPM, Verhey FRJ, Van Boxtel MPJ. A systematic review of social support interventions for caregivers of people with dementia: Are they doing what they promise? Maturitas. 2016;85:117-30.

36. Vasileiou K, Barnett J, Barreto M, et al. Experiences of Loneliness Associated with Being an Informal Caregiver: A Qualitative Investigation. Front Psychol. 2017;8:585.

37. Shiba K, Kondo N, Kondo K. Informal and formal social support and caregiver burden: The AGES caregiver survey. J Epidemiol. 2016;26(12):622-8. 